\title{
Role of the Prognostic Nutritional Index in Patients With Soft-tissue Sarcoma
}

\author{
YUMI MATSUYAMA, TOMOKI NAKAMURA, KEISUKE YOSHIDA, \\ KOICHI NAKAMURA, TOMOHITO HAGI, KUNIHIRO ASANUMA and AKIHIRO SUDO
}

Department of Orthopedic Surgery, Mie University Graduate School of Medicine, Tsu, Japan

\begin{abstract}
Background: This study aimed to determine whether the prognostic nutritional index (PNI) can predict the prognosis in patients with soft-tissue sarcoma (STS) before treatment and to examine whether there is an association between PNI values and clinical characteristics. Patients and Methods: The data on 100 patients with primary STS were retrospectively reviewed. The cohort included 55 men and 45 women, with a mean age of 64 years. The mean follow-up duration was 41.7 months. Results: The median PNI was 51.35. The PNI was significantly inversely associated with tumor size, tumor grade, and age. We found that the PNI was a significant prognostic marker for disease-specific and event-free survival using univariate and multivariate analyses. Patients with a low PNI had poorer disease-specific and event-free survival than those with a high PNI. Conclusion: These results suggest that the PNI can be used as a prognostic marker in patients with STS.
\end{abstract}

Soft-tissue sarcoma (STS) is a rare, heterogeneous group of tumors (1). The incidence of STS is fewer than six per 100,000 cancer cases, which represents $1-2 \%$ cases of all cancer in adults (1). Despite recent advances in the diagnosis and treatment of STS, patients who develop metastasis have high mortality rates. Therefore, many studies have attempted to define different factors for predicting the prognosis of patients with STS. Older age and deep, trunkal, high-grade, and large size of STS have been reported to be prognostic factors that are linked to poor prognosis (2-4). In addition, systemic inflammation has been associated with poor

This article is freely accessible online.

Correspondence to: Tomoki Nakamura, Department of Orthopaedic Surgery, Mie University Graduate School of Medicine, 2-174 Edobashi, Tsu-city, Mie, 514-8507, Japan. Tel: +81 592315022, Fax: +81 592315211, e-mail: tomoki66@med.mie-u.ac.jp

Key Words: Prognostic nutritional index, soft tissue sarcoma, survival. prognosis. In terms of STS, elevated levels of C-reactive protein and interleukin-6, hypoalbuminemia, and anemia have been correlated with poor oncological outcomes (5-9). In addition to the systemic inflammation status, nutrition and immune status play important roles in the prognosis of patients with several types of cancer (10-14).

The prognostic nutritional index (PNI), calculated using the serum albumin level and total lymphocyte count, is an effective indicator for assessing nutritional and immunological conditions. Initially described by Onodera et al. (15), it has been validated as an independent prognostic factor in several types of cancer, including renal cell cancer (10), pancreatic cancer (11), colorectal cancer (12), esophageal carcinoma (13), and hepatocellular carcinoma (14). However, it is unclear whether the PNI is useful in predicting the prognosis of patients with STS.

Therefore, this study aimed to determine whether the PNI can predict the prognosis in patients with STS before treatment and examine whether there is an association between PNI values and clinical characteristics.

\section{Patients and Methods}

Patient characteristics. Between February 2002 and April 2019, 100 patients with primary STS were retrospectively reviewed. Patients with recurrent disease and those who were referred for additional resection after a previous unplanned excision were excluded from this study. The study cohort included 55 men and 45 women, with a mean age of 64 years (range $=12-88$ years) at the time of diagnosis. The mean follow-up duration was 41.7 months (range $=0.6-208$ months). Histological diagnosis and tumor grade were determined using the French Federation of Cancer Centers Sarcoma Group grading system (15). The PNI values were calculated from preoperative laboratory parameters using the formula $10 \times$ serum albumin level $(\mathrm{g} / \mathrm{dl})+0.005 \times$ lymphocyte count $(\mathrm{n} / \mu \mathrm{l})$ in the peripheral blood (16). Serum albumin levels and lymphocyte counts were measured before the initial treatment in all patients.

Clinicopathological analysis was performed relating the PNI to various factors, including age, sex, and tumor grade, size, and depth.

The primary study aim was to examine the prognostic factors associated with patient survival, including the PNI, using univariate and multivariate analyses. The following factors were studied: age ( $\geq 66 v s$. 
Table I. The relationship between the prognostic nutritional index (PNI) and clinicopathological characteristics.

\begin{tabular}{lllcc}
\hline Variable & & $\mathrm{N}$ & Average PNI & $p$-Value \\
\hline Age & $<64$ Years & 42 & 51.65 & 0.33 \\
\multirow{3}{*}{ Gender } & $\geq 64$ Years & 58 & 50.42 & \\
& Male & 55 & 51.25 & 0.58 \\
Tumor depth & Female & 45 & 50.56 & \\
& Superficial & 12 & 52.02 & 0.52 \\
Tumor size & Deep & 88 & 50.79 & \\
\multirow{2}{*}{ Tumor grade } & $<10 \mathrm{~cm}$ & 49 & 52.79 & 0.0003 \\
& $>10 \mathrm{~cm}$ & 51 & 49.16 & \\
& Low & 33 & 52.96 & 0.020 \\
& High & 67 & 49.89 & \\
\hline
\end{tabular}

Table II. Spearman's correlation between the prognostic nutritional index (PNI) and tumor size and age as continuous variables.

\begin{tabular}{lcc}
\hline Variable & Spearman rho & $p$-Value \\
\hline Tumor size & -0.271 & 0.006 \\
Age & -0.242 & 0.015 \\
\hline
\end{tabular}

$<66$ years), sex, tumor grade ( 1 vs. 2 and 3), tumor size ( $>10 \mathrm{~cm} v s$. $<10 \mathrm{~cm}$ ), tumor depth, and PNI. The secondary aim was to examine the prognostic factors associated with oncological outcomes. Written informed consent was obtained from the patients. This study was approved by the Institutional Review Board at our hospital (no. 1310).

Statistical analysis. The statistical associations of the clinicopathological factors were evaluated using the Mann-Whitney $U$-test for quantitative data and the chi-square test for qualitative data. Disease-specific survival (DSS) was defined as the time from the initial surgery to the date of death from sarcoma. Event-free survival (EFS) was defined as the time from surgery to disease recurrence/metastasis. DSS and EFS curves were constructed using the Kaplan-Meier method, and the log-rank test was used to compare survival and oncological events. Univariate and multivariate analyses were performed using the Cox proportional hazards model. The variables included in the multivariate analysis were significant factors identified in univariate analysis. A value of $p<0.05$ was considered significant in all statistical analyses.

\section{Results}

A total of 100 patients were included in this study. The tumors were classified histologically as follows: 60 Liposarcomas (28 well-differentiated, 16 de-differentiated, six myxoid, and one pleomorphic), 15 myxofibrosarcomas, nine undifferentiated pleomorphic sarcomas and rhabdomyosarcomas, four malignant peripheral nerve sheath tumors and synovial sarcomas, and eight tumors of other histological types. The histological diagnoses and tumor grades were determined using the French Federation of Cancer Centers Sarcoma

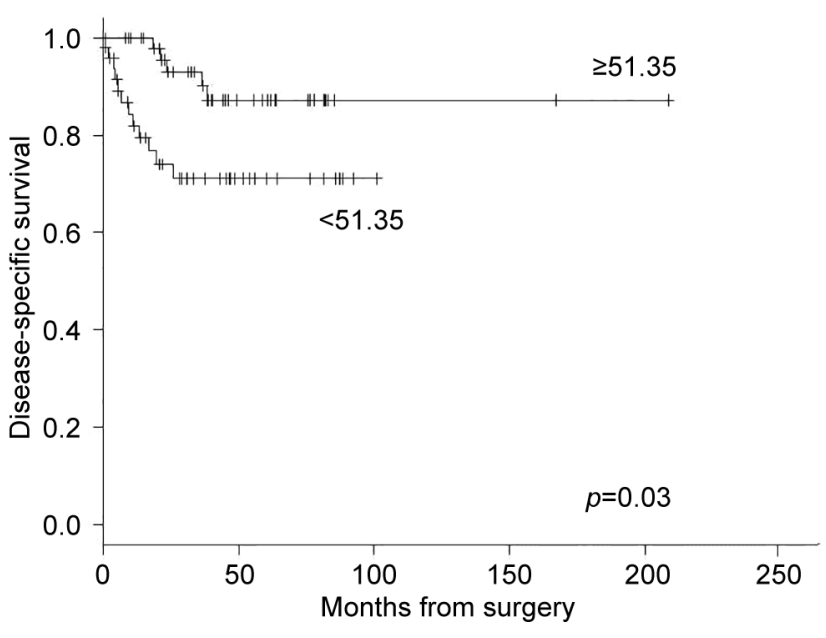

Figure 1. Kaplan-Meier curve showing the disease-specific survival for 100 patients with soft-tissue sarcoma according to prognostic nutritional index (PNI) using a cut-off of 51.35.

Group grading system (15). A total of 33 patients had grade 1 sarcomas, and 67 patients had grade 2 or 3 sarcomas. The mean tumor size at diagnosis was $11.8 \mathrm{~cm}$ (range $=1-38 \mathrm{~cm}$ ). The tumor depth was superficial and deep in 12 and 88 patients, respectively. Primary tumor resection was performed in all patients. A total of 23 patients received radiotherapy, and 33 patients received chemotherapy.

The median preoperative albumin level was $4.2 \mathrm{~g} / 1$ (range $=2.5-5.0 \mathrm{~g} / 1$ ), and the median lymphocyte count was 1640 cells $/ \mu 1$ (range $=380-3,560$ cells $/ \mu \mathrm{l}$ ) considering the whole patient cohort. The median PNI value was 51.35 (mean=50.94, range=31.2-65.75). The relationships between clinicopathological characteristics and PNI are shown in Table I. Tumor grade and size were significantly inversely associated with the PNI. Spearman's rank test showed that PNI values were weakly correlated with tumor diameter and age (Table II).

At the final follow-up, $82(82 \%)$ patients were alive, 16 (16\%) patients had died of the disease, and 2 (2\%) patients had died of other causes. The DSS at 5 years was $78.5 \%$ [95\% confidence interval $(\mathrm{CI})=67.8-86 \%$ ].

When patients were divided into two groups according to the median PNI value (51.35), those with a low PNI had poorer DSS than those with a high PNI (Figure 1). The 5year DSS rate was $71.1 \%(95 \% \mathrm{CI}=54.4-82.6 \%)$ in patients with a low PNI, whereas that in patients with a high PNI was $87.2 \%(95 \% \mathrm{CI}=71.7-94.5 \%)(p=0.03)$. Univariate analysis of all possible prognostic factors confirmed the predictive value of age $(p=0.046)$, histological grade $(p=0.003)$, and the PNI $(p=0.003)$. Histological grade and the PNI were considered to be of prognostic significance in multivariate analysis (Table III). 
Table III. The prognostic factors for disease-specific survival (DSS) in 100 patients with soft-tissue sarcoma.

\begin{tabular}{|c|c|c|c|c|c|c|}
\hline \multirow[b]{2}{*}{ Variable } & \multirow[b]{2}{*}{ Subgroup } & \multirow[b]{2}{*}{$\mathrm{N}$} & \multicolumn{2}{|c|}{ Univariate analysis } & \multicolumn{2}{|c|}{ Multivariate analysis } \\
\hline & & & 5-Y DSS & $p$-Value & HR $(95 \% \mathrm{CI})$ & $p$-Value \\
\hline \multirow[t]{2}{*}{ Age } & $<66$ Years & 45 & $89.4 \%$ & 0.046 & 1 & \\
\hline & $\geq 66$ Years & 55 & $70.2 \%$ & & $1.04(0.999-1.09)$ & 0.057 \\
\hline \multirow[t]{2}{*}{ Gender } & Male & 55 & $75.8 \%$ & 0.45 & & \\
\hline & Female & 45 & $83.8 \%$ & & & \\
\hline \multirow[t]{2}{*}{ Tumor depth } & Superficial & 12 & $91.7 \%$ & 0.36 & & \\
\hline & Deep & 88 & $77.5 \%$ & & & \\
\hline \multirow[t]{2}{*}{ Tumor size } & $<10 \mathrm{~cm}$ & 49 & $85.9 \%$ & 0.19 & & \\
\hline & $>10 \mathrm{~cm}$ & 51 & $72.7 \%$ & & & \\
\hline \multirow[t]{2}{*}{ Tumor grade } & Low & 33 & $96.4 \%$ & 0.003 & 1 & 0.04 \\
\hline & High & 67 & $68.1 \%$ & & $8.901(1.034-61.39)$ & \\
\hline \multirow[t]{2}{*}{ PNI } & $\geq 51.35$ & 51 & $85.4 \%$ & 0.03 & $0.9112(1.001-1.007)$ & 0.009 \\
\hline & $<51.35$ & 49 & $71.1 \%$ & & 1 & \\
\hline
\end{tabular}

CI: Confidence interval; HR: hazard risk; PNI: prognostic nutritional index, 5-Y: 5-year.

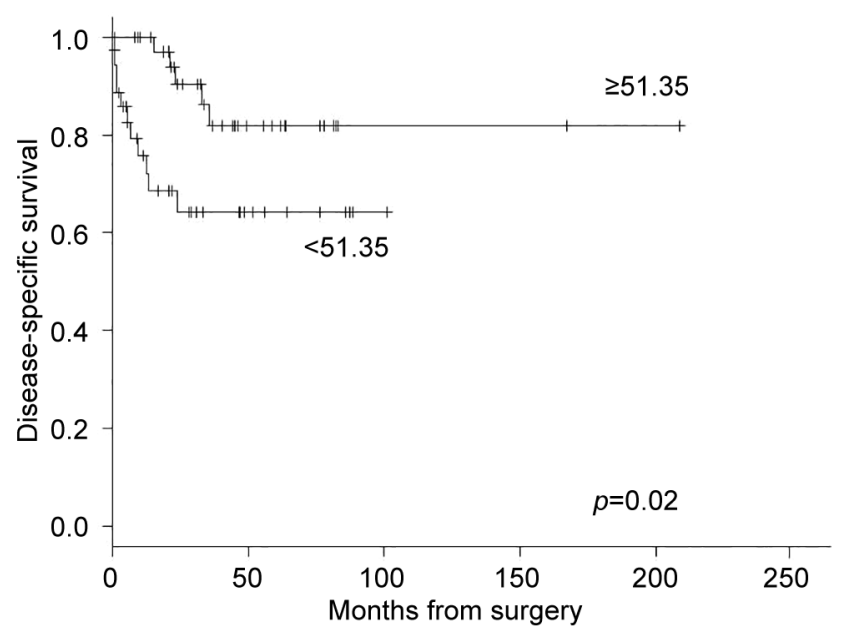

Figure 2. Kaplan-Meier curve showing the disease-specific survival for 74 patients with soft-tissue sarcoma, after exclusion of those with welldifferentiated liposarcoma, according to prognostic nutritional index (PNI) using a cut-off of 51.35 .

Next, we excluded 26 patients with well-differentiated liposarcoma from our cohort due to their excellent prognosis and examined the relationship between PNI and survival in the remaining 74 patients. The median PNI value was 51.35 (mean $=50.37$, range $=31.2-65.75)$ in 74 patients. Patients with a low PNI had poorer DSS than those with a high PNI $(p=0.02)$. The 5-year DSS rate was $64.3 \%$ (95\% CI=44.3$78.7 \%$ ) for patients with a low PNI, while that for those with a high PNI was $81.9 \%$ (95\% CI=61.3-92.1\%) (Figure 2). Univariate analysis of all possible prognostic factors confirmed the prognostic significance of tumor size $(p=0.045)$, age $(p=0.02)$, and the PNI $(p=0.02)$ (Table IV).

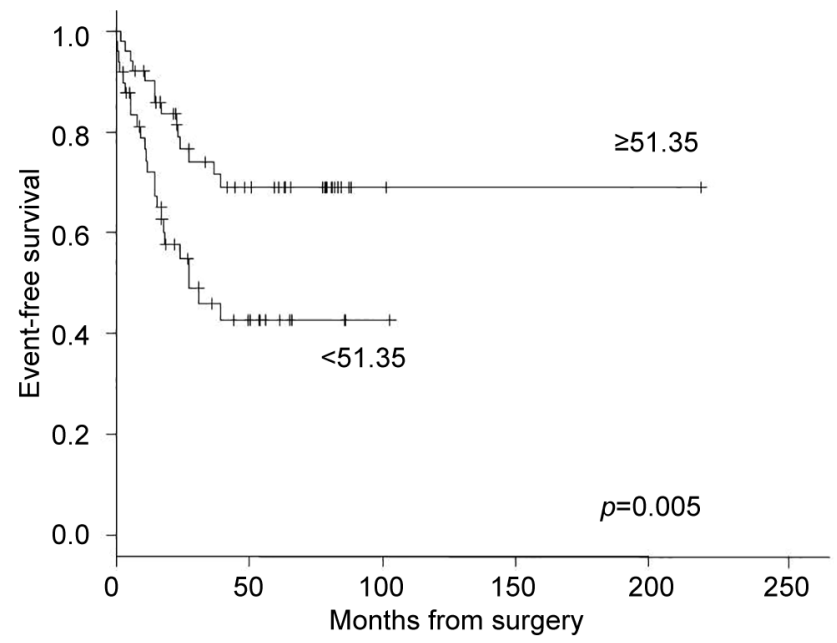

Figure 3. Kaplan-Meier curve showing the event-free survival for 100 patients with soft-tissue sarcoma according to prognostic nutritional index (PNI) using a cut-off of 51.35 .

Considering the whole cohort, recurrence and metastasis were observed in $15(15 \%)$ and 30 (30\%) patients, respectively. The EFS rate was $60.4 \%$ (95\% CI=48.5$70.4 \%$ ). Patients with a low PNI had a poorer EFS than those with a high PNI (Figure 3). The 5-year EFS rate was $42.7 \%$ (95\% CI=27.0-57.6\%) in patients with a low PNI, while that in those with a high PNI was $71.5 \%$ (95\% CI=55.8-82.55).

Univariate and multivariate analyses showed that a low PNI and high histological grade were independent predictors of recurrence/metastasis (Table $\mathrm{V}$ ).

Next, we excluded 26 patients with well-differentiated liposarcoma and examined the relationship between the PNI 
Table IV. The prognostic factors for disease-specific survival (DSS) in patients with soft-tissue sarcoma after exclusion of 26 with well-differentiated liposarcoma $(n=74)$.

\begin{tabular}{|c|c|c|c|c|c|c|}
\hline \multirow[b]{2}{*}{ Variable } & \multirow[b]{2}{*}{ Subgroup } & \multirow[b]{2}{*}{$\mathrm{N}$} & \multicolumn{2}{|c|}{ Univariate analysis } & \multicolumn{2}{|c|}{ Multivariate analysis } \\
\hline & & & 5-Y DSS & $p$-Value & HR $(95 \%$ CI $)$ & $p$-Value \\
\hline \multirow[t]{2}{*}{ Age } & $<66$ Years & 35 & $89.2 \%$ & 0.02 & 1 & \\
\hline & $\geq 66$ Years & 39 & $60.3 \%$ & & $1.046(1.001-1.093)$ & 0.046 \\
\hline \multirow[t]{2}{*}{ Gender } & Male & 38 & $68.6 \%$ & 0.46 & & \\
\hline & Female & 36 & $79.1 \%$ & & & \\
\hline \multirow[t]{2}{*}{ Tumor depth } & Superficial & 8 & $91.7 \%$ & 0.36 & & \\
\hline & Deep & 66 & $77.5 \%$ & & & \\
\hline \multirow[t]{2}{*}{ Tumor size } & $<10 \mathrm{~cm}$ & 42 & $83.7 \%$ & 0.045 & 1 & \\
\hline & $>10 \mathrm{~cm}$ & 32 & $56.5 \%$ & & $1.059(0.9842-1.139)$ & 0.13 \\
\hline \multirow[t]{2}{*}{ Tumor grade } & Low & 7 & $100 \%$ & 0.19 & & \\
\hline & High & 67 & $70.8 \%$ & & & \\
\hline \multirow[t]{2}{*}{ PNI } & $\geq 51.35$ & 38 & $81.9 \%$ & 0.02 & $0.9241(0.8536-1.000)$ & 0.051 \\
\hline & $<51.35$ & 36 & $64.3 \%$ & & 1 & \\
\hline
\end{tabular}

CI: Confidence interval; HR: hazard risk; PNI: prognostic nutritional index, 5-Y: 5-year.

and events. Patients with a low PNI had a poorer EFS than those with a high PNI $(p=0.02)$. The 5-year EFS rate was $39.8 \%(95 \% \mathrm{CI}=21.4-57.7 \%)$ in patients with low PNI, while that in those with a high PNI was $58.6 \%$ (95\% CI=38.4-74.2\%) (Figure 4). Univariate analysis of all possible prognostic factors confirmed the prognostic ability of tumor histology $(p=0.03)$, age $(p=0.03)$, and the PNI $(p=0.02)$. The PNI remained a significant factor in multivariate analysis (Table VI).

\section{Discussion}

Onodera et al. developed the PNI as an index to screen for the feasibility of surgery for gastrointestinal cancer (15). It is useful as an index not only for perioperative complications but also for prognosis prediction. It has been validated as an independent prognostic factor in several types of cancer (1015). In this study, using univariate and multivariate analyses, we found that the PNI was a significant prognostic marker for DSS and EFS in 100 patients with STS. When we excluded 26 patients with well-differentiated liposarcoma, the PNI significantly predicted EFS $(p=0.008)$ in multivariate analysis, although the PNI showed marginal significance for DSS ( $p=0.051)$. These results suggest that PNI is a prognostic marker in patients with STS.

The PNI reflects not only the nutritional and immune status but also the inflammatory status of patients $(7,17,18)$. A low PNI is caused by a low albumin level and/or lymphocyte count. Serum albumin is an important indicator of inflammatory reaction and nutritional status $(3,19)$. Several studies have previously demonstrated that high levels of the cytokine interleukin-6 contribute to the development of hypoalbuminemia and elevated C-reactive protein level $(8,20)$.

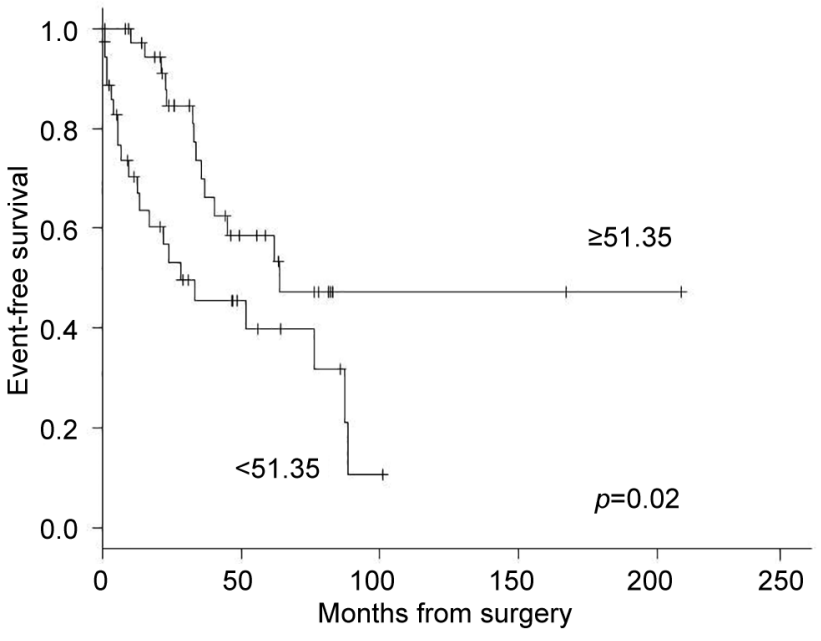

Figure 4. Kaplan-Meier curve showing the event-free survival for 74 patients with soft-tissue sarcoma, after exclusion of those with welldifferentiated liposarcoma, according to prognostic nutritional index (PNI) using a cut-off of 51.35 .

The combination of hypoalbuminemia and an elevated Creactive protein level, which are used in the Glasgow prognostic score or the high-sensitivity modified Glasgow prognostic score, has been shown to provide additional prognostic information in patients with STS $(2,5,6)$. Lymphocytes, the other element considered in the PNI, are the most important type of peripheral blood cells and work against the proliferation, migration, and invasion by cancer cells (21). Therefore, in the case of lymphocytopenia, the cellular immune system cannot function properly and an appropriate inflammatory reaction cannot be 
Table V. The prognostic factors for event-free survival (EFS) in 100 patients.

\begin{tabular}{|c|c|c|c|c|c|c|}
\hline \multirow[b]{2}{*}{ Variable } & \multirow[b]{2}{*}{ Subgroup } & \multirow[b]{2}{*}{$\mathrm{N}$} & \multicolumn{2}{|c|}{ Univariate analysis } & \multicolumn{2}{|c|}{ Multivariate analysis } \\
\hline & & & 5-Y DSS & $p$-Value & HR $(95 \%$ CI $)$ & $p$-Value \\
\hline \multirow[t]{2}{*}{ Age } & $<66$ Years & 45 & $69.5 \%$ & 0.1 & & \\
\hline & $\geq 66$ Years & 55 & $49.0 \%$ & & & \\
\hline \multirow[t]{2}{*}{ Gender } & Male & 55 & $54.5 \%$ & 0.66 & & \\
\hline & Female & 45 & $62.3 \%$ & & & \\
\hline \multirow[t]{2}{*}{ Tumor depth } & Superficial & 12 & $91.7 \%$ & 0.36 & & \\
\hline & Deep & 88 & $77.5 \%$ & & & \\
\hline \multirow[t]{2}{*}{ Tumor size } & $<10 \mathrm{~cm}$ & 49 & $59.4 \%$ & 0.59 & & \\
\hline & $>10 \mathrm{~cm}$ & 51 & $56.3 \%$ & & & \\
\hline \multirow[t]{2}{*}{ Tumor grade } & Low & 33 & $89.3 \%$ & $<0.0001$ & 1 & $<0.001$ \\
\hline & High & 67 & $41.0 \%$ & & $7.67(2.318-25.38)$ & \\
\hline \multirow[t]{2}{*}{ PNI } & $\geq 51.35$ & 51 & $71.5 \%$ & 0.005 & $0.9204(0.8706-0.9729)$ & 0.001 \\
\hline & $<51.35$ & 49 & $42.7 \%$ & & 1 & \\
\hline
\end{tabular}

CI: Confidence interval; HR: hazard risk; PNI: prognostic nutritional index, 5-Y: 5-year.

Table VI. The prognostic factors for event-free survival (EFS) in patients with soft-tissue sarcoma after exclusion of 26 with well-differentiated liposarcoma $(n=74)$.

\begin{tabular}{|c|c|c|c|c|c|c|}
\hline \multirow[b]{2}{*}{ Variable } & \multirow[b]{2}{*}{ Subgroup } & \multirow[b]{2}{*}{$\mathrm{N}$} & \multicolumn{2}{|c|}{ Univariate analysis } & \multicolumn{2}{|c|}{ Multivariate analysis } \\
\hline & & & 5-Y DSS & $p$-Value & HR $(95 \%$ CI $)$ & $p$-Value \\
\hline \multirow[t]{2}{*}{ Age } & $<66$ Years & 35 & $58.7 \%$ & 0.03 & 1 & 0.36 \\
\hline & $\geq 66$ Years & 39 & $42.1 \%$ & & $1.012(0.9864-1.038)$ & \\
\hline \multirow[t]{2}{*}{ Gender } & Male & 38 & $45.1 \%$ & 0.41 & & \\
\hline & Female & 36 & $55.3 \%$ & & & \\
\hline \multirow{2}{*}{ Tumor depth } & Superficial & 8 & $44.3 \%$ & 0.09 & & \\
\hline & Deep & 66 & $87.5 \%$ & & & \\
\hline \multirow[t]{2}{*}{ Tumor size } & $<10 \mathrm{~cm}$ & 42 & $65.0 \%$ & 0.07 & & \\
\hline & $>10 \mathrm{~cm}$ & 32 & $30.7 \%$ & & & \\
\hline \multirow{2}{*}{ Tumor grade } & Low & 7 & $100 \%$ & 0.03 & 1 & 0.99 \\
\hline & High & 67 & $45.5 \%$ & & $5.344 \times 107$ (0.0-infinity) & \\
\hline \multirow[t]{2}{*}{ PNI } & $\geq 51.35$ & 38 & $58.6 \%$ & 0.02 & $0.9253(0.8732-0.9805)$ & 0.008 \\
\hline & $<51.35$ & 36 & $39.8 \%$ & & 1 & \\
\hline
\end{tabular}

CI: Confidence interval; HR: hazard risk; PNI: prognostic nutritional index, 5-Y: 5-year.

established. Therefore, the PNI is an index that reflects chronic inflammation, the immune system, and nutritional status and has prognostic significance in cancer patients. In this study, tumor size and grade were associated with PNI. Therefore, a low PNI may be indicative of the action of an aggressive tumor in patients with STS. Recently, the PNI was shown to be an independent prognostic factor for progression-free survival in patients with metastatic breast cancer who were treated with eribulin (22). Eribulin is also administered to patients with STS, and future studies should be conducted to investigate possible markers of survival.

This study has some limitations. There is no 'normal' value established for PNI, and it may be difficult to confirm its validity in different cohorts. The cutoff value used for predicting survival ranges from 40 to 52.8 in several types of cancer (10$15,22-33)$, a range which includes that of the present study (51.35). However, several other markers, such as the neutrophillymphocyte ratio and platelet-lymphocyte ratio for predicting DSS in patients with STS, have standard levels because of the nature of their calculation methods (2, 34). Systemic inflammatory diseases such as collagen disease were not considered, although all patients underwent initial screening, including computed tomography of the chest and routine blood examinations before their treatment. The retrospective design of this study is another limitation. However, we believe that the PNI could be a useful prognostic marker in patients with STS. 


\section{Conflicts of Interest}

There were no conflicts of interest in this study.

\section{Authors' Contributions}

Tomoki Nakamura and Yumi Matsuyama conceived the study, collected and analyzed the data and wrote the article. Keisuke Yoshida, Koichi Nakamura and Tomohito Hagi analyzed and interpreted the clinical data. Akihiro Sudo and Kunihiro Asanuma interpreted the clinical data, and reviewed the article.

\section{References}

1 Bourcier K, Le Cesne A, Tselikas L, Adam J, Mir O, Honore C and de Baere T: Basic knowledge in soft tissue sarcoma. Cardiovasc Intervent Radiol 42(9): 1255-1261, 2019. PMID: 31236647. DOI: $10.1007 / \mathrm{s} 00270-019-02259-\mathrm{w}$

2 Sasaki H, Nagano S, Komiya S, Taniguchi N and Setoguchi T: Validation of different nutritional assessment tools in predicting prognosis of patients with soft tissue spindle-cell sarcomas. Nutrients 10(6): 765, 2018. PMID: 29899304. DOI: 10.3390/ nu10060765

3 Ogura K, Higashi T and Kawai A: Statistics of soft-tissue sarcoma in Japan: Report from the Bone and Soft Tissue Tumor Registry in Japan. J Orthop Sci 22(4): 755-764, 2017. PMID: 28601416. DOI: 10.1016/j.jos.2017.03.017

4 Stojadinovic A, Leung DH, Hoos A, Jaques DP, Lewis JJ and Brennan MF: Analysis of the prognostic significance of microscopic margins in 2,084 localized primary adult soft tissue sarcomas. Ann Surg 235(3): 424-434, 2002. PMID: 11882765. DOI: 10.1097/00000658-200203000-00015

5 Nakamura T, Grimer R, Gaston C, Carter S, Tillman R, Abudu A, Jeys L and Sudo A: The relationship between pretreatment anaemia and survival in patients with adult soft tissue sarcoma. J Orthop Sci 18(6): 987-993, 2013. PMID: 23943226. DOI: 10.1007/s00776-013-0454-6

6 Hou T, Guo T, Nie R, Hong D, Zhou Z, Zhang X and Liang Y: The prognostic role of the preoperative systemic immuneinflammation index and high-sensitivity modified Glasgow prognostic score in patients after radical operation for soft tissue sarcoma. Eur J Surg Oncol 46(8): 1496-1502, 2020. PMID: 32576479. DOI: $10.1016 /$ j.ejso.2020.05.026

7 Nakamura T, Matsumine A, Asanuma K, Matsubara T and Sudo A: The value of the high-sensitivity modified Glasgow prognostic score in predicting the survival of patients with a soft-tissue sarcoma. Bone Joint J 97-B(6): 847-852, 2015. PMID: 26033068. DOI: 10.1302/0301-620X.97B.35098

8 Nakamura T, Katagiri H, Shido Y, Hamada S, Yamada K, Nagano A, Yamada S, Tsukushi S, Ishimura D, Matsumine A, Sudo A and Nishida Y: Analysis of factors for predicting survival in soft-tissue sarcoma with metastatic disease at initial presentation. Anticancer Res 37(6): 3137-3141, 2017. PMID: 28551655. DOI: 10.21873 /anticanres.11671

9 Nakamura K, Nakamura T, Iino T, Hagi T, Kita K, Asanuma K and Sudo A: Expression of interleukin-6 and the interleukin-6 receptor predicts the clinical outcomes of patients with soft tissue sarcomas. Cancers (Basel) 12(3): 585, 2020. PMID: 32138303. DOI: $10.3390 /$ cancers 12030585

10 Hofbauer SL, Pantuck AJ, de Martino M, Lucca I, Haitel A, Shariat SF, Belldegrun AS and Klatte T: The preoperative prognostic nutritional index is an independent predictor of survival in patients with renal cell carcinoma. Urol Oncol 33(2): 68.e1-68.e7, 2015. PMID: 25240758. DOI: 10.1016/j.urolonc. 2014.08.005

11 Kanda M, Fujii T, Kodera Y, Nagai S, Takeda S and Nakao A: Nutritional predictors of postoperative outcome in pancreatic cancer. Br J Surg 98(2): 268-274, 2011. PMID: 20960457. DOI: 10.1002/bjs.7305

12 Nozoe T, Kohno M, Iguchi T, Mori E, Maeda T, Matsukuma A and Ezaki T: The prognostic nutritional index can be a prognostic indicator in colorectal carcinoma. Surg Today 42(6): 532-535, 2012. PMID: 22139087. DOI: 10.1007/s00595-011-0061-0

13 Sakai M, Sohda M, Miyazaki T, Yoshida T, Kumakura Y, Honjo H, Hara K, Ozawa D, Suzuki S, Tanaka N, Yokobori T and Kuwano H: Association of preoperative nutritional status with prognosis in patients with esophageal cancer undergoing salvage esophagectomy. Anticancer Res 38(2): 933-938, 2018. PMID: 29374724. DOI: 10.21873 /anticanres.12306

14 Kinoshita A, Onoda H, Imai N, Iwaku A, Oishi M, Fushiya N, Koike K, Nishino $\mathrm{H}$ and Tajiri $\mathrm{H}$ : Comparison of the prognostic value of inflammation-based prognostic scores in patients with hepatocellular carcinoma. Br J Cancer 107(6): 988-993, 2012. PMID: 22878374. DOI: 10.1038/bjc.2012.354

15 Guillou L, Coindre JM, Bonichon F, Nguyen BB, Terrier P, Collin F, Vilain MO, Mandard AM, Le Doussal V, Leroux A, Jacquemier J, Duplay H, Sastre-Garau X and Costa J: Comparative study of the National Cancer Institute and French Federation of Cancer Centers Sarcoma Group grading systems in a population of 410 adult patients with soft tissue sarcoma. J Clin Oncol 15(1): 350-362, 1997. PMID: 8996162. DOI: 10.1200/JCO.1997.15.1.350

16 Onodera T, Goseki N and Kosaki G: [Prognostic nutritional index in gastrointestinal surgery of malnourished cancer patients]. Nihon Geka Gakkai Zasshi 85(9): 1001-1005, 1984. PMID: 6438478.

17 Feng Z, Wen H, Ju X, Bi R, Chen X, Yang W and Wu X: The preoperative prognostic nutritional index is a predictive and prognostic factor of high-grade serous ovarian cancer. BMC Cancer 18(1): 883, 2018. PMID: 30200903. DOI: 10.1186/ s12885-018-4732-8

18 Fang E, Wang X, Feng $\mathrm{J}$ and Zhao X: The prognostic role of Glasgow prognostic score and $\mathrm{C}$-reactive protein to albumin ratio for sarcoma: A system review and meta-analysis. Dis Markers 2020: 8736509, 2020. PMID: 31998420. DOI: $10.1155 / 2020 / 8736509$

19 Don BR and Kaysen G: Serum albumin: relationship to inflammation and nutrition. Semin Dial 17(6): 432-437, 2004. PMID: 15660573. DOI: 10.1111/j.0894-0959.2004.17603.x

20 McMillan DC, Watson WS, O'Gorman P, Preston T, Scott HR and McArdle CS: Albumin concentrations are primarily determined by the body cell mass and the systemic inflammatory response in cancer patients with weight loss. Nutr Cancer 39(2): 210-213, 2001. PMID: 11759282. DOI: 10.1207/ S15327914nc392_8

21 Wu ES, Oduyebo T, Cobb LP, Cholakian D, Kong X, Fader AN, Levinson KL, Tanner EJ 3rd, Stone RL, Piotrowski A, Grossman 
S and Roche KL: Lymphopenia and its association with survival in patients with locally advanced cervical cancer. Gynecol Oncol 140(1): 76-82, 2016. PMID: 26571200. DOI: 10.1016/j.ygyno. 2015.11.013

22 Oba T, Maeno K, Ono M, Ito T, Kanai T and Ito KI: Prognostic nutritional index is superior to neutrophil-to-lymphocyte ratio as a prognostic marker in metastatic breast cancer patients treated with eribulin. Anticancer Res 41(1): 445-452, 2021. PMID: 33419842. DOI: 10.21873/anticanres.14794

23 Mori S, Usami N, Fukumoto K, Mizuno T, Kuroda H, Sakakura N, Yokoi K and Sakao Y: The significance of the prognostic nutritional index in patients with completely resected non-small cell lung cancer. PLoS One 10(9): e0136897, 2015. PMID: 26356222. DOI: 10.1371/journal.pone.0136897

24 Mohri T, Mohri Y, Shigemori T, Takeuchi K, Itoh Y and Kato T: Impact of prognostic nutritional index on long-term outcomes in patients with breast cancer. World J Surg Oncol 14(1): 170, 2016. PMID: 27349744. DOI: 10.1186/s12957-016-0920-7

25 Yao ZH, Tian GY, Wan YY, Kang YM, Guo HS, Liu QH and Lin DJ: Prognostic nutritional index predicts outcomes of malignant pleural mesothelioma. J Cancer Res Clin Oncol 139(12): 21172123, 2013. PMID: 24149776. DOI: 10.1007/s00432-013-1523-0

26 Watanabe M, Iwatsuki M, Iwagami S, Ishimoto T, Baba Y and Baba H: Prognostic nutritional index predicts outcomes of gastrectomy in the elderly. World J Surg 36(7): 1632-1639, 2012. PMID: 22407085. DOI: 10.1007/s00268-012-1526-z

27 Migita K, Takayama T, Saeki K, Matsumoto S, Wakatsuki K, Enomoto K, Tanaka T, Ito M, Kurumatani N and Nakajima Y: The prognostic nutritional index predicts long-term outcomes of gastric cancer patients independent of tumor stage. Ann Surg Oncol 20(8): 2647-2654, 2013. PMID: 23463091. DOI: 10.1245/s10434-013-2926-5

28 Proctor MJ, Morrison DS, Talwar D, Balmer SM, Fletcher CD, O'Reilly DS, Foulis AK, Horgan PG and McMillan DC: A comparison of inflammation-based prognostic scores in patients with cancer. A Glasgow Inflammation Outcome Study. Eur J Cancer 47(17): 2633-2641, 2011. PMID: 21724383. DOI: 10.1016/j.ejca.2011.03.028
29 Maeda K, Shibutani M, Otani H, Nagahara H, Sugano K, Ikeya T, Kubo N, Amano R, Kimura K, Muguruma K, Tanaka H and Hirakawa K: Low nutritional prognostic index correlates with poor survival in patients with stage IV colorectal cancer following palliative resection of the primary tumor. World J Surg 38(5): 1217-1222, 2014. PMID: 24305937. DOI: 10.1007/ s00268-013-2386-X

30 Mohri Y, Inoue Y, Tanaka K, Hiro J, Uchida K and Kusunoki M: Prognostic nutritional index predicts postoperative outcome in colorectal cancer. World J Surg 37(11): 2688-2692, 2013. PMID: 23884382. DOI: $10.1007 / \mathrm{s} 00268-013-2156-9$

31 Pinato DJ, North BV and Sharma R: A novel, externally validated inflammation-based prognostic algorithm in hepatocellular carcinoma: the prognostic nutritional index (PNI). Br J Cancer 106(8): 1439-1445, 2012. PMID: 22433965. DOI: $10.1038 /$ bjc.2012.92

32 Wang DS, Luo HY, Qiu MZ, Wang ZQ, Zhang DS, Wang FH, $\mathrm{Li} \mathrm{YH}$ and $\mathrm{Xu} \mathrm{RH}$ : Comparison of the prognostic values of various inflammation based factors in patients with pancreatic cancer. Med Oncol 29(5): 3092-3100, 2012. PMID: 22476808. DOI: $10.1007 / \mathrm{s} 12032-012-0226-8$

33 Feng JF and Chen QX: Significance of the prognostic nutritional index in patients with esophageal squamous cell carcinoma. Ther Clin Risk Manag 10: 1-7, 2014. PMID: 24379675. DOI: 10.2147/TCRM.S56159

34 Nakamura T, Matsumine A, Matsubara T, Asanuma K, Uchida A and Sudo A: The combined use of the neutrophil-lymphocyte ratio and C-reactive protein level as prognostic predictors in adult patients with soft tissue sarcoma. J Surg Oncol 108(7): 481-485, 2013. PMID: 24018883. DOI: 10.1002/jso.23424

Received April 5, 2021

Revised April 30, 2021

Accepted May 5, 2021 